\title{
Survival of treponemes after treatment: comments, clinical conclusions, and recommendations
}

\author{
ERIC M C DUNLOP \\ From the Whitechapel Clinic, The London Hospital; the Diagnostic Clinic, Moorfields Eye Hospital; and \\ the Institute of Ophthalmology, London
}

SUMMARY Treponemes may persist after treatment that has been accepted as effective; the reasons for this are discussed. Nevertheless, the epidemic of syphilis after the second world war was not followed by an epidemic of late syphilis, and the results of treatment with penicillin are excellent.

Neurological signs may progress in some treated patients, and the standard doses of soluble penicillin and any dose of benzathine penicillin (even with added probenecid by mouth) cannot be relied on to achieve treponemicidal concentrations in the cerebrospinal fluid (CSF). There are no large scale studies of CSF findings after treatment of early syphilis with benzathine penicillin.

Standard dosage, such as procaine penicillin G 600000 international units (IU) by intramuscular injection for 10 days, is the treatment of choice for the patient suffering from uncomplicated early syphilis; this should be preferred to benzathine penicillin, which should only be used when standard treatment as above cannot be given.

Treponemicidal concentrations of penicillin should be achieved in the CSF of patients suffering from neurosyphilis by schedules of probenecid by mouth and procaine penicillin by single daily intramuscular injections; treatment should last for 17 to 21 days. Benzathine penicillin should not be used for the treatment of patients suffering from neurosyphilis or from the iritis of late syphilis including that accompanying interstitial keratitis. Treatment for interstitial keratitis should initially be as for neurosyphilis, but in recurrent cases it may have to be prolonged to eradicate Treponema pallidum that is dividing slowly.

Doxycycline $300 \mathrm{mg}$ by mouth daily for 21 days provides a supervisable outpatient schedule for patients allergic to penicillin. Cephaloridine (and probably cefuroxime and the new cephalosporins) may be useful for patients who are allergic to penicillin but have not developed anaphylactic allergy.

If erythromycin is used for treating syphilis in pregnant women who are allergic to penicillin, then the newborn babies should be treated with penicillin.

\section{Introduction}

Treponemes may survive what has been considered to be adequate treatment of syphilis. Virulent Treponema pallidum has been recovered from cerebrospinal fluid (CSF) or the eye from some patients who had been treated for early syphilis with penicillin (including benzathine penicillin). What

Address for reprints: Dr E M C Dunlop, 26 Old School Lane, Milton, Cambridge CB4 4BS

Accepted for publication 1 February 1985

Based on Dunlop EMC. Comments on the survival of treponemes after therapy. WHO/INT/VDT/80 1980;365: 1-15. have been generally accepted as adequate regimens of penicillin (including all dosage levels of benzathine penicillin) demonstrably do not achieve treponemicidal levels of penicillin in the CSF. The progression of neurosyphilis after "adequate" treatment has been noted. These findings are considered, and some conclusions are drawn.

\section{Late syphilis after early syphilis treated with penicillin}

Nearly 40 years have elapsed since the immediate postwar epidemic of early syphilis was treated with penicillin. If treponemes commonly survive such 
treatment in forms able to cause lesions of late syphilis there would now be a high incidence of such manifestations. That this has not happened (figure) ${ }^{1} 2$ is one of the major benefits of penicillin.

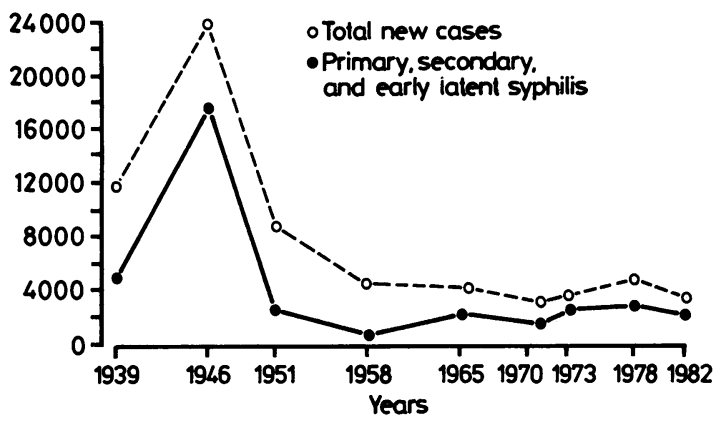

FIGURE Syphilis in England and Wales 1939-82.

Results of treatment of early syphilis were excellent; ${ }^{2} 3$ most patients who were treated again had probably been reinfected. ${ }^{3}$ Thus in most cases of early syphilis treated with conventional courses of penicillin the treponemes were destroyed or, if they survived, they did so in forms that did not produce disease in man.

The decline in late syphilis, including general paralysis of the insane (GPI), ${ }^{4}$ has continued (figure). Results of treatment of late syphilis with penicillin were good. ${ }^{2}$ Prognosis depends on the lack of tissue damage at the start of treatment. The earlier the treatment was started the better was the prognosis.

Penicillin by itself was the drug of choice for the treatment of neurosyphilis, ${ }^{5}$ including asymptomatic neurosyphilis ${ }^{6}$ and GPI. ${ }^{7}$ Nevertheless, clinical follow up for 10 years or more by Wilner and Brody of 64 patients with paresis who had been treated with penicillin showed new clinical signs of neurological involvement in 25.8 Thus long term follow up suggested that in some cases of late syphilis treponemes might survive after treatment with penicillin, although in general results were good.

\section{Laboratory evidence of survival of treponemes after treatment}

This has been obtained by two methods: the direct detection of treponemal forms by microscopy of body fluids or tissues, or by the infection (shown by microscopy) of experimental animals, usually rabbits, after their inoculation with body fluids or tissues.
The characteristic morphology and motility of $T$ pallidum may be shown by dark field microscopy of wet preparations. The examination of fixed specimens has the disadvantages of distortion of tissue and loss of treponemal motility. The organism may be stained with silver (and many dyes), which may give variable and unpredictable results, ${ }^{9}$ or the background may be stained. Alternatively, the more specific fluorescent antibody staining may be used for smears and tissues.

\section{PERSISTING TREPONEMES DETECTED BY MICROSCOPY}

Studies were reported initially by Collart et al in France in $1962^{10}$ and reviewed in $1964^{11}$ and then by workers in the United States of America, the United Kingdom, and India. Tests gave low yields of positive findings so that in one series only $42(19 \%)$ of 223 patients with treated or untreated syphilis gave positive results. 12

Some organisms were artefacts, ${ }^{13} 14$ whereas $T$ pallidum could be transferred to previously blank slides during fluorescent staining and washing. ${ }^{15}$ In the absence of proved infection of an experimental animal a treponeme like form in man cannot be accepted with certainty as being pathogenic $T$ pallidum.

\section{INFECTION OF EXPERIMENTAL ANIMALS}

Six groups of workers infected animals with syphilis by inoculation with material from patients who might have persisting treponemes, ${ }^{10} 1116-20$ but one of these groups found positive infectivity test results only after "inadequate" treatment. ${ }^{19}$ Turner et al stressed the importance of the positive infectivity test in rabbits. ${ }^{21}$ Such inoculation is insensitive, however, even in early syphilis, so only eight of 15 transfers of infectious material from patients with primary or secondary syphilis resulted in infection. ${ }^{22}$

\section{How does $T$ pallidum survive?}

Some factors to be considered are:

\section{STAGE OF DISEASE}

In late compared with early syphilis the infection is relatively inactive, and organisms are presumably dividing at a much slower rate than the 30 to 33 hour division time of $T$ pallidum in early syphilis of experimentally infected rabbits. ${ }^{23} 24$

As the organism replicates, penicillin links with transpeptidase catalases forming an inactive complex, so that the treponemal cell wall is not synthesised or repaired. Thus some organisms that are not dividing during treatment may survive. Collart et al incubated virulent $T$ pallidum for 15 hours in Nelson-Mayer medium, in which they do not replicate, with penicillin $1000 \mathrm{IU} / \mathrm{ml}$ to 10000 
$\mathrm{IU} / \mathrm{ml}{ }^{25}$ After the penicillin had been destroyed by penicillinase the treponemes still caused syphilitic orchitis in rabbits.

Magnuson and Eagle showed that incubating syphilis in rabbits could be cured or aborted by only $1 / 32$ of the curative dose if given within three days of inoculation. ${ }^{26}$ The dose required in early syphilis increased with the duration of infection and the number of spirochaetes present. The smaller the inoculum and the earlier the penicillin was administered the greater was its suppressive effect.

Late latent syphilis in rabbits is more resistant to treatment than early syphilis as measured by positive lymph node transfers and seroconversion in recipient animals. ${ }^{27}$ Because $T$ pallidum divides slowly in late syphilis, recurrences may be reduced by prolonging the duration of treponemicidal concentrations of penicillin in eyes affected by interstitial keratitis. The organism recovered by Hardy et al, however, was obtained after treating a newborn baby for early congenital syphilis (see special sites of infectioneye). ${ }^{18}$

\section{MICROBIAL PERSISTENCE}

McDermott used this term for the fact that some organisms survive attack by antibiotics to which they are fully sensitive. ${ }^{28}$ Thus if $T$ pallidum behaves like other organisms, occasional treatment failure without obvious cause is to be expected.

\section{SPECIAL SITES OF INFECTION \\ Central nervous system}

Smith et al reported a cumulative failure rate of $21 \%$ 18 months after treating patients for asymptomatic neurosyphilis with injections of benzathine penicillin G 2.4 MIU or 2.5 MIU, compared with $10.5 \%$ for other preparations of penicillin. ${ }^{29}$ Increasing the dose of benzathine penicillin to $4.8 \mathrm{MIU}$ given in two injections of 2.4 MIU seven to 10 days apart did not reduce the failure rate, which was 33\% (8/24 followed up), if CSF cell counts of over $5 / \mathrm{mm}^{3}$ after six months or more are accepted as abnormal..$^{30}$ Thus even $4.8 \mathrm{MIU}$ of benzathine penicillin is an inefficient preparation for treating neurosyphilis.

$T$ pallidum has been detected in CSF from a patient three weeks after treatment with $10.8 \mathrm{MIU}$ of benzathine penicillin $\mathrm{G}$ for neurosyphilis. ${ }^{20}$ Failure to achieve treponemicidal concentrations in CSF has been reported with intramuscular injections of benzathine penicillin $G^{31-34}$ even after a total dose as high as $14.4 \mathrm{MIU}$ (4.8 MIU weekly for three weeks) in all of nine cases, ${ }^{33}$ in four of six given this dose and probenecid by mouth, ${ }^{33}$ and in 12 of 13 given 3.6 MIU weekly for four weeks. 31

In newborn babies intramuscular injections of benzathine penicillin $G 100000 \mathrm{IU} / \mathrm{kg}$ produced CSF concentrations of 0.012 to 0.21 (mean 0.06 ) $\mathrm{mg} / \mathrm{l}$ for up to 24 hours after injection. Five out of 10 specimens of CSF did not contain treponemicidal concentrations at 48 hours, and no penicillin was detected in the five specimens tested at 120 hours. ${ }^{35}$ Intramuscular injections of procaine penicillin $G$ $50000 \mathrm{IU} / \mathrm{kg}$ daily without accompanying probenecid produced treponemicidal CSF concentrations in newborn babies. ${ }^{36}$

Procaine penicillin $\mathrm{G}$ alone or with $2 \%$ aluminium monostearate (PAM) 600000 IU daily by intramuscular injection achieved treponemicidal concentrations in the blood but not the CSF. ${ }^{37-42}$ Procaine penicillin $600000 \mathrm{IU}$ gave such a concentration in the CSF of one out of six patients, $1.2 \mathrm{MIU}$ in two out of seven, $1.8 \mathrm{MIU}$ in one out of two, and 2.4 MIU in two out of three. ${ }^{41}$ The cumulative concentration of penicillin after intramuscular injection of procaine penicillin 600000 IU daily for 14 to 21 days was treponemicidal in the serum but not the CSF of 10 patients. ${ }^{40}$ The addition of probenecid by mouth produced treponemicidal CSF concentrations in six out of 11.40

The addition of probenecid $500 \mathrm{mg}$ by mouth every six hours to various regimens produced treponemicidal CSF concentrations as follows: procaine penicillin G 600000 IU daily by intramuscular injection in two out of three patients, ${ }^{38}$ procaine penicillin $1.2 \mathrm{MIU}$ daily in four out of five patients, ${ }^{38}$ benzyl penicillin 500000 IU every six hours in all of 31 patients, ${ }^{38}$ procaine penicillin 2.4 MIU once daily in all of 38 patients, ${ }^{42}$ and procaine penicillin $1.8 \mathrm{MIU}$ once daily in all of 12 patients. ${ }^{42}$ The last regimen is practical for outpatients. ${ }^{43}$ It produced CSF penicillin concentrations of $0.06-1.8 \mathrm{mg} / \mathrm{l}$. A wide margin above the treponemicidal concentration of $0.018 \mathrm{mg} / 1$ is probably desirable to allow for error in the method of estimation and because in animals the penicillin concentration in the brain may be about one tenth of that in the CSF, ${ }^{44}$ and probenecid increases brain concentrations less than it increases CSF concentrations. 45

Oral administration of amoxycillin $1 \mathrm{~g}$ six times a day with probenecid $2 \mathrm{~g}$ a day produced treponemicidal amoxycillin concentrations $(>0.42 \mathrm{mg} / \mathrm{l})$ three and nine hours after the last dose. ${ }^{46}$ This suggests that a $3 \mathrm{~g}$ sachet of amoxycillin twice a day (possibly once a day) with probenecid would produce even higher CSF concentrations, which would be maintained by probenecid. This is under review. Such a schedule might be used for the supervised treatment of outpatients suffering from neurosyphilis.

\section{Eye}

Drugs sparingly soluble in lipids, such as the penicillins, ${ }^{47} 48$ achieve low concentrations in the 
ocular compartments. ${ }^{48}$ Ampicillin penerrates aqueous humour more effectively than penicillin G. ${ }^{49-51}$ Concentrations of the penicillins in the eye are increased from about $6 \%$ to $50 \%$ of the serum concentrations by inflammation ${ }^{48}$ and by probenecid. Concentrations of penicillin achieved in the vitreous humour and lens of animals are about one third to one fifth of those in the aqueous humour. ${ }^{48}$

Acute iritis occurs in almost $5 \%$ of patients with early secondary syphilis and in just over $9 \%$ of recurrent cases. 52 It responds promptly to conventional antisyphilitic treatment, as does subclinical iritis in secondary syphilis diagnosed by slit lamp microscopy..$^{53}$ Severe inflammation that aids the penetration of antibiotics may not be a prominent feature of syphilitic infection of the eye or CNS. Because $T$ pallidum has been isolated from normal CSF, CSF changes clearly understate the incidence of neurological involvement. ${ }^{54}$

Virulent $T$ pallidum fully sensitive to penicillin was isolated by the inoculation of rabbits with aqueous humour and eye tissue (but not liver) from a baby infected with congenital syphilis who died aged 22 days. ${ }^{18}$ The mother had been treated for secondary syphilis before pregnancy with an unknown amount of tetracycline and in the seventh month of pregnancy with benzathine penicillin G $2.4 \mathrm{MU}$ intramuscularly. The baby was delivered 10 days later, and a treponemicidal concentration of penicillin was present in the cord blood. The baby then received benzyl penicillin $50000 \mathrm{IU} / \mathrm{kg} / \mathrm{day}$ intramuscularly for 17 days. At autopsy a non-motile treponeme was present in the aqueous humour, and a similar one had been found in the CSF on the 10th day of life.

\section{UNCHANGED INTRACELLULAR FORMS OF $T$ PALLIDUM}

$T$ pallidum may be found within the cytoplasm and nuclei of cells by electron microscopy. 55-60 Treponemes are taken up by macrophages and polymorphonuclear leucocytes, where they are destroyed. Virulent $T$ pallidum may enter cells that are incapable of complete phagocytosis, such as fibroblasts, where they remain unchanged, or virtually unchanged (as in plasma cells). Penetration of cells in tissue culture is rapid and may occur within 30 minutes of inoculation. ${ }^{61}$ This intracellular position may be important because it may play a part in the development of the host's immune response, may protect $T$ pallidum from the action of penicillin in extracellular fluid, and because the superoxide dismutase in host cells may protect $T$ pallidum against high tissue concentrations of oxygen. ${ }^{62}$

With the exception of rifampicin, which has no action against $T$ pallidum, short courses of antibiotics do not enter living mammalian cells. If they are administered for about seven days, however, they do enter some mammalian cells. ${ }^{63}$

"ZONE PHENOMENON" OF EAGLE

Penicillin acts upon growing organisms. Tipper and Strominger showed that low concentrations of penicillin acting upon Staphylococcus aureus caused the production of cell walls that were deficient in peptide cross linkages and the accumulation in the cells of nascent peptidoglycan units. ${ }^{64} \mathrm{High}$ concentrations of penicillin rapidly inhibit growth of the organisms so that defective cell walls are not produced and nascent peptidoglycan units do not collect. This may explain the fact that the killing rate of low concentrations of penicillin for Staph aureus was higher than that of high concentrations (the "zone phenomenon" of Eagle). It is unknown whether this applies to $T$ pallidum. The baby reported by Hardy et $a^{18}$ had received low level benzathine penicillin in utero and high level penicillin $G$ by injection after birth. Despite this, virulent $T$ pallidum gave a positive infectivity test result.

\section{Biology of $T$ pallidum related to treatment ${ }^{63} 65$}

\section{STRUCTURE OF T PALLIDUM}

Treponemes contain ribosomes, which are presumably acted on by erythromycin and tetracyclines, and have cell walls. In summary, penicillin acts by interfering with the synthesis of cell walls. It is only active against organisms that synthesise their cell walls in growth and division.

\section{TREPONEMAL REPRODUCTION}

A sexual reproductive phase, which could serve as a means of transmission of resistance to antibiotics as it does in Gram negative bacteria, has been postulated.

The 30 to 33 hour division time for $T$ pallidum ${ }^{23} 24$ is for organisms from lesions of early syphilis. If the treponemes in a patient suffering from late syphilis are dividing more slowly or not dividing at all, the requirements for their elimination may well be different from those of treponemes in early syphilis. If a treponemicidal concentration of penicillin is present but the organisms are not dividing, they remain viable, virulent, and unaffected by the drug. ${ }^{25}$

If the intervals between doses are too great they will allow treponemal recovery between doses. Thus in early syphilis short intervals between doses are appropriate if a soluble penicillin is used, and a dose that produces a treponemicidal concentration for an appreciable proportion of the life of each generation will be required. In early syphilis it seems that treatment should be for no less than seven and a half days, or six generations. In late syphilis very long lasting penicillinaemia may occasionally be required. 
DOSE AND DURATION OF TREPONEMICIDAL CONCENTRATIONS

Motility and virulence of $T$ pallidum are not synonymous. Organisms that still remain motile after in vitro incubation with penicillin may be unable to infect rabbits, ${ }^{66} 67$ but infection cannot be caused by treponemes that have been immobilised by penicillin.

Raising the concentration of penicillin increases its effect until an optimum concentration has been attained; higher concentrations do not increase the effect. This applies to Reiter treponemes, ${ }^{68}$ to the immobilisation of virulent $T$ pallidum after an initial lag phase of four hours with pure penicillin, ${ }^{69}$ to syphilitic orchitis in rabbits, ${ }^{70}$ and to the time taken for chancres to become negative on dark field microscopy. ${ }^{71}$ The dose of any antimicrobial agent must have a sufficient margin to provide treponemicidal concentrations for the required time. This must allow for microbial variations and differences in absorption due to the size, age, and activity of the patient and the preparation used. ${ }^{72}$

In man a treponemicidal serum concentration of $0.03 \mathrm{IU} / \mathrm{ml}(0.018 \mathrm{mg} / \mathrm{l})$ lasts for seven days after intramuscular administration of benzathine penicillin G 300000 IU, nine days after 600000 IU, and about 21 to 24 days after 2.4 to 3 MIU. Treponemicidal CSF concentrations, however, are generally not achieved by this preparation (see above).

If short acting penicillins are used, the duration of effective penicillinaemia increases with increasing dosage. A sequence of large doses may be more effective than even larger infrequent doses because it avoids appreciable gaps and (particularly if given with probenecid by mouth) may produce effective concentrations in the CSF and eye. Intramuscular injections of benzyl penicillin G 500000 IU every six hours, or procaine penicillin G 1.8 MIU daily, with probenecid by mouth can be relied on to produce treponemicidal CSF penicillin concentrations (see above).

Studies of treatment of early experimental syphilis in rabbits with penicillin suggest that very high doses of aqueous penicillin are wasteful and that about eight days is the optimum duration of treatment. In each experiment the amount of penicillin required to cure $50 \%$ or $100 \%$ of the rabbits was less if it was given in the form of depot injections. If the duration of treatment was fixed at eight days, then aqueous penicillin given twice a day was as effective as a single depot injection daily. ${ }^{63}$

\section{ENCYSTMENT OF T PALLIDUM}

Treponemes in chancres in man may be encysted. ${ }^{56}$ They may be motile ${ }^{73}$ within a variable enclosing wall that is thought to represent a protective early ${ }^{73}$ or degenerative ${ }^{74}$ reaction to noxious stimuli.
"CAPSULE"

A clear zone $^{75}$ or extracellular layer ${ }^{76}$ surrounds $T$ pallidum in syphilitic lesions. This might reduce phagocytosis and be a barrier to low concentrations of antibiotics. ${ }^{76}$

RESISTANCE OF T PALLIDUM TO PENICILLIN

There is some evidence of reduced sensitivity to penicillin of $T$ pallidum after its passage in rabbits that were treated subcuratively. ${ }^{77-79}$ Collart and Poitevin, however, could not produce true penicillin resistance after repeated passages in and subcurative treatment of rabbits for seven years. ${ }^{80}$ Apparently, strains of $T$ pallidum consisted of heterogenous groups with different multiplication times.

Treatment failure has never been shown to be due to resistance of $T$ pallidum to penicillin. ${ }^{18}$

WEAK PENICILLIN

This has not been a factor since penicillin was standardised as penicillin $\mathrm{G}$.

ORAL TREATMENT OF PATIENTS WITH SYPHILIS Moore stated that, because of poor patient compliance, treatment of syphilis should be by injection. ${ }^{81}$ Because high concentrations of amoxycillin can probably now be achieved reliably by doses once or twice daily together with probenecid by mouth, the objections to oral treatment with the penicillins are less applicable. For patients who are allergic to penicillin, doxycycline $300 \mathrm{mg}$ once daily may be given under supervision.

\section{PROBENECID WITH PENICILLINS AND \\ AMPICILLIN}

Fishman showed that the effect of probenecid on CSF penicillin concentrations was to raise blood concentrations, to inhibit excretion of penicillin from the CSF, and to bind serum protein so that diffusable penicillin was released. The concentration in the brain was also increased, but to a lesser extent than in the CSF. ${ }^{45}$ In patients being treated for neurosyphilis, probenecid increased the CSF penicillin concentration by a factor of 6 and the CSF ampicillin concentration by a factor of $3 .^{82}$ Probenecid raised the concentrations of ampicillin 5083 and penicillin 50 in the eye.

\section{Antitreponemal drugs other than penicillin $\mathbf{G}$}

\section{AMPICILLIN}

Ampicillin $500 \mathrm{mg}$ four times a day for 10 days provides effective treatment for early syphilis if the antibiotic is taken as ordered and diarrhoea does not develop. The peak blood concentration is 2 to $2.5 \mathrm{mg} / \mathrm{l}$, and the half life two hours. Probenecid 
extends the half life and increases the penetration of the eye and the CSF. Talampicillin, which is metabolised to ampicillin, causes less gastrointestinal disturbance and fewer sensitivity rashes.

\section{AMOXYCILLIN}

Amoxycillin promises to be even more useful. The antitreponemal equivalent of $0.018 \mathrm{mg} / 1$ of penicillin is $0.42 \mathrm{mg} / \mathrm{l}$ of amoxycillin, which is easily reached and maintained, even in the CSF, with probenecid. ${ }^{46}$ It is better absorbed than ampicillin, and causes fewer sensitivity reactions and less gastrointestinal disturbance.

\section{CEPHALOSPORINS \\ Cephaloridine}

Cephaloridine has treponemicidal activity about one tenth that of penicillin, so it is more effective than the tetracyclines or chloramphenicol.

If a patient has developed non-anaphylactic allergy to penicillin treatment and has normal renal function, closely supervised treatment with cephaloridine $1 \mathrm{~g}$ intramuscularly twice daily for 15 days (for uncomplicated early syphilis) or for 21 days (for complicated syphilis) is effective. Cross sensitivity to cephaloridine may be present or will develop in less than $10 \%$ of patients. For this reason cephalosporins are absolutely contraindicated in patients who have had an anaphylactic reaction to penicillin.

\section{Cephalexin}

Cephalexin has a half life of about $\mathbf{4 0}$ minutes, so would require administration by mouth four times a day. The problems posed by patient non-compliance make it an unsuitable preparation for the treatment of syphilis.

\section{Cefuroxime}

Cefuroxime has been shown to have considerable effect against $T$ pallidum in vitro, as the minimum immobilising concentration is about 10 times greater than that of penicillin G. ${ }^{84}$ Cefuroxime enters the CSF in meningitis in man. ${ }^{85}$

\section{CHLORAMPHENICOL}

Chloramphenicol has weak antitreponemal activity but penetrates the CSF and eye well because it is lipophilic and has a small molecule. It causes dose independent or dose related aplastic anaemia, so should not be used for treating syphilis.

\section{ERYTHROMYCIN}

The estolate produces high blood concentrations and probably more hepatitis than other preparations. Although this has been denied, ${ }^{86}$ the drug is best avoided at present. The antitreponemal action of erythromycin approximates to that of the tetracyclines, but absorption is variable and the drug does not enter the CSF or eye or cross the placenta effectively. ${ }^{87} 88$ At least five cases have been reported of erythromycin apparently curing early syphilis in pregnant women who subsequently gave birth to children affected by active congenital syphilis. ${ }^{89-92}$ Erythromycin should not be used for treating neurosyphilis.

LINCOMYCIN, CLINDAMYCIN, METRONIDAZOLE, AND VANCOMYCIN

These four drugs have some action against $T$ pallidum but insufficient for therapeutic use. The aminoglycosides have very little effect so that, with the possible exception of spectinomycin, they can be used to treat gonorrhoea without invalidating a diagnosis of early syphilis.

\section{TETRACYCLINES}

Doxycycline and methacycline are usually either as effective as tetracycline or 10 times more effective against cultivable treponemes. ${ }^{93} 94$ The tetracyclines are considerably less effective than penicillin $G$ in vitro and in vivo. Positive infectivity test results have followed the administration of an unknown amount of tetracycline ${ }^{18}$ and tetracycline hydrochloride $2 \mathrm{~g}$ a day for 10 days. ${ }^{20}$

Tetracycline hydrochloride $500 \mathrm{mg}$ by mouth yields a serum concentration of $3.5 \mathrm{mg} / 1$ with a half life of six to nine hours. Doxycycline $200 \mathrm{mg}$ yields the same concentration with a half life of 17 to 20 hours. 95 Doxycycline and minocycline are well absorbed from the gut and enter the eye and CSF more effectively than tetracycline. ${ }^{96}$ Absorption is not impaired by milk or milk products. Tetracyclines stain teeth and cause embryopathy and are therefore contraindicated in pregnant women and young children. Doxycycline particularly causes photosensitivity, so direct sunshine should be avoided during and for three days after the course of treatment.

\section{Clinical conclusions and recommendations}

The standard treatment of early syphilis with procaine penicillin $600000 \mathrm{IU}$, with or without $2 \%$ aluminium monostearate, by daily intramuscular injection for $\mathbf{1 0}$ days has proved to be highly effective and is the treatment of choice.

The value of depot injections of benzathine penicillin is less certain for early syphilis, and no large scale studies include CSF findings. There is no evidence that results are improved by intramuscular injections of $2.4 \mathrm{MU}$ for adults at intervals of two 
weeks to a total of 2,3 , or 4 injections. ${ }^{97}$ Even this dose cannot be relied on to eliminate treponemes from the CSF.

It is logical to maintain a treponemicidal CSF penicillin concentration $(0.018 \mathrm{mg} / \mathrm{l})$ in treating neurosyphilis by intramuscular injections of benzyl penicillin G 500000 IU every six hours together with probenecid $500 \mathrm{mg}$ by mouth for 17-21 days. Alternatively, procaine penicillin $1.8 \mathrm{MIU}$ intramuscularly and probenecid by mouth daily for 17-21 days is suitable for outpatients.

IRITIS OF LATE SYPHILIS, EITHER CONGENITAL (WITH INTERSTITIAL KERATITIS) OR ACQUIRED Treatment should be at least as intensive as for neurosyphilis, and in a patient suffering from recurrent interstitial keratitis may have to be prolonged (using, say, talampicillin or amoxycillin with probenecid) to eradicate infrequently dividing organisms.

\section{TREATMENT WITH ANTIBIOTICS OTHER THAN PENICILLIN}

Doxycycline is the tetracycline of choice. It can be administered daily in a single supervised $300 \mathrm{mg}$ dose (with milk after eating) for 15 days to treat early uncomplicated syphilis or for 21 days to treat complicated or late syphilis.

Cephaloridine $1 \mathrm{~g}$ twice a day intramuscularly is useful for patients who have had a non-anaphylactic allergic reaction to penicillin. It may be given for 15 days to treat early uncomplicated syphilis or for 21 days to treat complicated or late syphilis.

Erythromycin $500 \mathrm{mg}$ (with milk after eating) four times a day for 21 days may be used for patients who cannot tolerate penicillin or doxycycline. It crosses natural barriers poorly and therefore hardly enters the eye, CSF, or fetus. If it is used for pregnant women, the newborn babies should be treated with procaine penicillin 300000 IU a day intramuscularly for 10 days. The mother's CSF should then be examined, and her treatment should be completed with doxycycline as required after breast feeding has stopped.

\section{FURTHER INFORMATION}

A regular computer search should be made to collect and assess further information on treatment with doxycycline, minocycline, and other tetracyclines; erythromycin; cephaloridine; the new cephalosporins; and amoxycillin. Finally the use of benzathine penicillin should be fully assessed.

\section{References}

1. Perdrup A. 20 Jahre Penicillinbehandlung der Spätlues (Kardiovasculare and Neurolues) Mit 1 Textabbildung. Archiv fur Klinische und Experimentelle Dermatologie 1964;219: 169-76.
2. Idsce O, Guthe T, Willcox RR. Penicillin in the treatment of syphilis. The experience of three decades. Bull WHO 1972; 47: $1-68$.

3. Jefferiss FJG, Willcox RR. Treatment of early syphilis with penicillin alone. British Journal of Venereal Diseases 1963;39: 143-8.

4. Martin JP. Conquest of general paralysis. Br Med J 1972; ii: 159-60.

5. Hahn RD, Lewis BI, Wiggall RH, Cross ES. The treatment of neurosyphilis with penicillin and with penicillin plus malaria. American Journal of Syphilis, Gonorrhea and Venereal Diseases 1951;35:433-70.

6. Hahn RD, Cutler JC, Curtis AC, et al. Penicillin treatment of asymptomatic central nervous system syphilis. AMA Archives of Dermatology and Syphilology 1956; 74:355-77.

7. Hahn RD, Webster B, Weickhardt G, et al. Penicillin treatment of general paresis (dementia paralytica). $A M A$ Archives of Neurology and Psychiatry 1959;81:557-90.

8. Wilner E, Brody JA. Prognosis of general paresis after treatment. Lancet 1968; ii:1370-1.

9. Turner TB, Hollander DH. Biology of the treponematoses. WHO Monograph Series; 1957; No 35: 101.

10. Collart P, Borel L-J, Durel P. Recherches sur l'efficacité de la pénicillinothérapie au course de la syphilis tardive expérimentale et humaine. Annales de Dermatologie et de Syphiligraphie 1962;89:488-504.

11. Collart P, Borel L-J, Durel P. Significance of spiral organisms found, after treatment, in late human and experimental syphilis. British Journal of Venereal Diseases 1964;40:81-9.

12. Dunlop EMC. Persistence of treponemes after treatment. Br Med J 1972; ii: 577-80.

13. Wilkinson AE. Study of late ocular syphilis. 1. Methods of demonstration of treponemes. Trans Ophthalmol Soc UK 1968;88:251-6.

14. Montenegro ENR, Nicol WG, Smith JL. Treponemalike forms and artifacts. Am J Ophthalmol 1969;68: 197-205.

15. Elsas FJ. The wandering treponeme. A possible source of error in fluorescent antibody staining of spiral bodies in body fluids. WHO/VDT/RES/71 1971:251:1-4.

16. Yobs AR, Clark JW Jr, Mothershed SE, Bullard JC, Artley $\mathrm{CW}$. Further observations on the persistence of Treponema pallidum after treatment in rabbits and humans. British Journal of Venereal Diseases 1968;44:116-30.

17. Smith JL, Israel CW, McCrary JA, Harner RE. Recovery of Treponema pallidum from aqueous humor removed at cataract surgery in man by passive transfer to rabbit testis. $A m ~ J$ Ophthalmol 1968; 65:242-7.

18. Hardy JB, Hardy PH, Oppenheimer EH, Ryan SJ, Sheff RN. Failure of penicillin in a newborn with congenital syphilis. JAMA 1970;212:1345-9.

19. Yogeswari $\mathrm{L}$, Chacko $\mathrm{CW}$. Persistence of $T$ pallidum and its significance in penicillin-treated late syphilis with persistence of seroreactivity. WHO/VDT/RES/72 1972;262:1-13.

20. Tramont EC. Persistence of Treponema pallidum following penicillin G therapy. Report of two cases. JAMA 1976;236: 2206-7.

21. Turner TB, Hardy PH, Newman B. Infectivity tests in syphilis. British Journal of Venereal Diseases 1969; 45: 183-96.

22. Collart $\mathbf{P}$, Dunoyer $\mathbf{M}$, Dunoyer $\mathbf{F}$. Résultats d'inoculations aux lapins de biopsies de lésions syphilitiques primosecondaires prélevées sur des malades non-traités. Annales de Dermatologie et de Syphiligraphie 1968;95:285-92.

23. Magnuson HJ, Eagle $H$, Fleischman $R$. The minimal infectious inoculum of Spirochaeta pallida (Nichols strain) and a consideration of its rate of multiplication in vivo. American Journal of Syphilis, Gonorrhea and Venereal Diseases 1948; 32:1-18.

24. Cumberland MC, Turner TB. The rate of multiplication of Treponema pallidum in normal and in immune rabbits. American Journal of Syphilis, Gonorrhea and Venereal Diseases 1949;33:201-12.

25. Collart $P$, Pechère JC, Franceschini $P$, Dunoyer $P$. Persisting virulence of $T$ pallidum after incubation with penicillin in Nelson-Mayer medium. British Journal of Venereal Diseases 1972; 48:29-31.

26. Magnuson $\mathbf{H J}$, Eagle $\mathrm{H}$. The retardation and suppression of experimental early syphilis by small doses of penicillin comparable to those used in the treatment of gonorrhea American Journal of Syphilis, Gonorrhea and Venereal Diseases, 1945; 29: 587-96. 
27. Ovcinnikov NM, Korbut SE, Bednova VN, Timcenko GF, Milonova TI. Long-term results of penicillin treatment of early and late forms of syphilis in the rabbit. British Journal of Venereal Diseases 1973;49:413-9.

28. McDermott W. Microbial persistence. Yale J Biol Med 1958; 30:257-91.

29. Smith CA, Kamp M, Olansky S, Price EV. Benzathine penicillin G in the treatment of syphilis. Bull WHO 1956; 15: $1087-96$

30. Short DH, Knox JM, Glicksman J. Neurosyphilis, the search for adequate treatment. Anch Dermatol 1966;93:87-91.

31. Mohr JA, Griffiths W, Jackson R, Saadah H, Bird P, Riddle $J$. Neurosyphilis and penicillin levels in cerebrospinal fluid. JAMA 1976; 236:2208-9.

32. Polnikorn $\mathbf{N}$, Witoonpanich $R$, Vorachit $M$, Vejjajiva $S$ Vejjajiva A. Penicillin concentrations in cerebrospinal fluid after different treatment regimens for syphilis. British Journal of Venereal Diseases 1980;56:363-7.

33. Ducas J, Robson H. Cerebrospinal fluid penicillin levels during therapy for latent syphilis. $J A M A 1981 ; 246: 2583-4$.

34. Polnikorn $N$, Witoonpanich $R$, Vorachit $M$, Vejjajiva $S$, Vejjajiva A. Penicillin concentrations in the cerebrospinal fluid after benzathine penicillin and probenecid in the treatment of syphilis. British Journal of Venereal Diseases 1982;58:342.

35. Speer ME, Taber LH, Clark DB, Rudolph AJ. Cerebrospinal fluid levels of benzathine penicillin $G$ in the neonate. J Pediatr 1977;91:996-7.

36. Speer ME, Mason EO, Scharnberg JT. Cerebrospinal fluid concentrations of aqueous procaine penicillin $\mathrm{G}$ in the neonate. $J$ Pediatr 1981;67:387-8.

37. Yoder FW. Penicillin treatment of neurosyphilis. Are recommended dosages sufficient? JAMA 1975;232:270-1.

38. Dunlop EMC, Al-Egaily S, Houang ET. Penicillin levels in blood and CSF achieved by treatment for syphilis. JAMA 1979; 241:2538-40.

39. Löwhagen G-B, Brorson J-E, Kaijser B. Penicillin concentrations in cerebrospinal fluid and serum after intramuscular, intravenous and oral administration to syphilitic patients. Acta Derm Venereol (Stockh) 1983;63:53-7.

40. Goh BT, Smith GW, Sarasinghe L, Singh V, Lim KS. Penicillin concentrations in serum and cerebrospinal fluid after intramuscular injection of aqueous procaine penicillin $0.6 \mathrm{MU}$ with and without oral probenecid. British Journal of Venereal Diseases 1984;60:371-3.

41. Goldmeier D, Waterworth PM, Penetration of penicillin into the cerebrospinal fluid of patients with latent syphilis. Pharmatherapeutica 1981;3:14-7.

42. Dunlop EMC, Al-Egaily SS, Houang ET. Production of treponemicidal concentration of penicillin in cerebrospinal fluid. $B r$ Med $J$ 1981; 283:646.

43. Manu $P$, Varade W. Penicillin therapy for asymptomatic neurosyphilis. In-patient intravenous or out-patient intramuscular? Lancet 1982; ii:924-5.

44. Barling RWA, Selkon JB. The penetration of antibiotics into cerebrospinal fluid and brain tissue. J Antimicrob Chemother 1978;4:203-27.

45. Fishman RA. Blood-brain and CSF barriers to penicillin and to related organic acids. Arch Neurol 1966; 15:113-24.

46. Faber WR, Bos JD, Rietra PJGM, Fass H, Van Eijk RVW. Treponemicidal levels of amoxycillin in cerebrospinal fluid after oral administration. Sex Transm Dis 1983:10:148-50.

47. Barza M. Factors affecting the intraocular penetration of antibiotics. Scand J Infect Dis [Suppl] 1978; 14:151-9.

48. Barza M, Baum J. Penetration of ocular compartments by penicillins. Surv Ophthalmol 1973; 18:71-82.

49. Goldman EE, McLain JH, Smith JL. Penicillins and aqueous humor. Am J Ophthalmol 1968;65:717-21.

50. Goldman JN, Klein JO. Penetration of ampicillin and penicillin G into aqueous humor. Ann Ophthalmol 1970;2: 35-42.

51. Kurose Y, Levy PM, Leopold IH. Intraocular penetration of ampicillin. II. Clinical experiment. Arch Ophthalmol 1965; 73: 366.

52. Moore JE. Syphilitic iritis. Am J Ophthalmol 1931;14:110-26.

53. Zwink FB, Dunlop EMC. Clinically silent anterior uveitis in secondary syphilis. Trans Ophthalmol Soc UK 1976;96: 148-50.

54. Chesney AM, Kemp JE, Incidence of Spirocheta pallida in cerebrospinal fluid during early stages of syphilis. JAMA 1924; 83:1725-8.

55. Azar HA, Pham TD, Kurban AK. Phagocytic engulfment of Treponema pallidum by plasma cells. WHO/VDT/RES/71 1971:255: 1-3.
56. Ovcinnikov NM, Delektorskij VV. Current concepts of the morphology and biology of Treponema pallidum based on electron microscopy. British Journal of Venereal Diseases 1971;47:315-28.

57. Sykes JA, Miller JN. Intracellular location of Treponema pallidum (Nichols strain) in the rabbit testis. Infect Immun 1971;4:307-14.

58. Ovcinnikov NM, Delektorskij VV. Electron microscopy of phagocytosis in syphilis and yaws. British Journal of Venereal Diseases 1972;48:227-48.

59. Lauderdale V, Goldman JN. Serial ultrathin sectioning demonstrating the intracellularity of Treponema pallidum. An electron microscopic study. British Journal of Venereal Diseases 1972:48:87-96.

60. Sykes JA, Miller JN, Kalan AJ. Treponema pallidum within cells of a primary chancre from a human female. British Journal of Venereal Diseases 1974; 50:40-4.

61. Fitzgerald TJ, Miller JN, Sykes JA. Treponema pallidum (Nichols strain) in tissue culture: cellular attachment, entry and survival. Infect Immun 1975; 11:1133-40.

62. Ovcinnikov NM, Delektorskij VV. Effect of crystalline penicillin and bicillin-1 on experimental syphilis in the rabbit. Electron microscope study. British Journal of Venereal Diseases 1972; 48:327-41.

63. Rein MF. Biopharmacology of syphilotherapy. Journal of the American Venereal Diseases Association 1976:3:109-26.

64. Tipper DJ, Strominger J.. Biosynthesis of peptidoglycan of bacterial cell walls. XII. Inhibition of cross-linking by penicillins and cephalosporins: studies in Staphylococcus aureus in vivo. $J$ Biol Chem 1968;243:3169-79.

65. Willcox RR, Guthe T. Treponema pallidum. A bibliographical review of the morphology, culture and survival of Treponema pallidum and associated organisms. Bull WHO 1966;35:1-169.

66. Clark JW Jr. Loss of virulence in vitro of motile Treponema pallidum in normal and immune rabbits. British Journal of Venereal Diseases 1962;38:78-81.

67. Dunham WB, Rake G. The relative activity of partially purified penicillin and of crystalline penicillin on Treponema pallidum. American Journal of Syphilis, Gonorrhea and Venereal Diseases 1945; 28:214-8.

68. Eagle $\mathrm{H}$. Therapeutic significance of penicillin blood levels. Ann Intern Med 1948; 28:260-78.

69. Nell EE. Comparative sensitivity of treponemes of syphilis, yaws and bejel to penicillin in vitro with observations on factors affecting its treponemicidal action. American Journal of Syphilis, Gonorrhea and Venereal Diseases 1954;38:92-106.

70. Eagle H, Fleischman R, Musselman AD. Effective concentrations of penicillin in vitro and in vivo for streptococcus, pneumococcus and Treponema pallidum. J Bacteriol 1950;59, 625-43.

71. Tucker HA, Robinson RCV. Disappearance time of Treponema pallidum from lesions of early syphilis following administration of crystalline penicillin G. Bulletin of the Johns Hopkins Hospital 1947; 80: 169-73.

72. Collart P, Poitevin M, Milanovic A, Herlin A, Durel J. Kinetic study of serum penicillin concentrations after single doses of benzathine and benethamine penicillins in young and old people. British Journal of Venereal Diseases 1980;56:355-62.

73. Ov'innikov NM, Delektorskij VV. Further studies of the morphology of Treponema pallidum under the electron microscope. British Journal of Venereal Diseases 1969;45: 87-116.

74. Hardy PH, Nell EE. Influence of osmotic pressure on the morphology of the Reiter treponeme. J Bacteriol 1961;82: 967-78.

75. Krause RM. Workshop on the biology of the treponemes. $J$ Infect Dis 1972; 125:332-6.

76. Zeigler JA, Jones AM, Jones RH, Kubica KM. Demonstration of extracellular material at the surface of pathogenic Treponema pallidum cells. British Journal of Venereal Diseases 1967;52:1-8.

77. Boak RA, Carpenter CM. Therapeutic efficacy of penicillin $G$ in experimental syphilis produced by four different strains of Treponema pallidum. American Journal of Syphilis, Gonorrhea and Venereal Diseases 1949;33: 8-11.

78. Dunham WB, Hamre DM, McKee CM, Rake G. Action of penicillin and other antibiotics on Treponema pallidum. Proc Soc Exp Biol Med 1944; 55: 158-60.

79. Zajac W. An attempt at separation of pathogenic treponemes, Nichols strain, of changed penicillin-sensitivity by means of in vivo experiments in rabbits. WHO/VDT/RES/75 1975;341: 1-8. (Cited by Rein MF. Biopharmacology of syphilotherapy. 
Journal of the American Venereal Diseases Association 1976; 3:109-26.)

80. Collart $P$, Poitevin M. Comparative study by a new method of the behaviour of a strain of Treponema pallidum passaged successively for seven years in rabbits that had been given subcurative penicillin therapy with the Nichols strain as control. WHO/VDT/RES/73 1973;307: 1-13.

81. Moore JE. Penicillin in syphilis. Oxford; Blackwell Scientific Publications, 1947:25.

82. Dewhurst $\mathbf{K}$. The use of probenecid for increasing penicillin concentrations in cerebrospinal fluid. Acta Neurol Scand 1969, 45:253-6.

83. Goldman JN. Clinical experience with ampicillin and probenecid in the management of treponeme-associated uveitis. Transactions of the Academy of Ophthalmology and Otolaryngology 1970; 74:509-14.

84. Xerri L, Orsolini P. In vitro activity of cefuroxime against Treponema pallidum. J Antimicrob Chemother 1978;4:189.

85. Muller C, Netland A, Dawson AF, Andrew E. The penetration of cefuroxime into the cerebrospinal fluid through inflamed and 'non-inflamed' meninges. J Antimicrob Chemother 1980; 6:279-83.

86. Inman WHW, Rawson NSB. Erythromycin estolate and jaundice. $\mathrm{Br}$ Med J 1983;286: 1954-5.

87. Kiefer L, Rubin A, McCoy JB, Foltz EL. Placental transfer of erythromycin. Am J Obstet Gynecol 1955;69:174-7.

88. Philipson A, Sabath LD, Charles D. Transplacental passage of erythromycin and clindamycin. N Engl J Med 1973;288: 1219-21.
89. South MA, Short DH, Knox JM. Failure of erythromycin estolate therapy in in utero syphilis. JAMA 1964;190:70-1.

90. Mamunes P, Cave VG, Budell JW, Andersen JA, Steward RE. Early diagnosis of neonatal syphilis. Am J Dis Child 1970; 120: 17-21.

91. Caldwell JG. Congenital syphilis. A non-venereal disease. $\mathrm{Am}$ J Nursing 1971;71:1768-72.

92. Fenton LJ, Light IJ. Congenital syphilis after maternal treatment with erythromycin. Obstet Gynecol 1976;47:492-4.

93. Abramson IJ, Smibert RM. Inhibition of growth of treponemes by antimicrobial agents. British Journal of Venereal Diseases 1971;47:407-12.

94. Abramson IJ, Smibert RM. Bactericidal activity of antimicrobial agents for treponemes. British Journal of Venereal Diseases 1971;47:413-8.

95. Weinstein L. Chemotherapy of microbial disease. In: Goodman LS, Gilman A, eds. The pharmacological basis of therapeutics. 5th ed. New York: MacMillan Publishing, 1975.

96. Barza M, Brown RB, Shanks C, Gamble C, Weinstein L. Relation between lipophilicity and pharmacological behaviour of minocycline, doxycycline, tetracycline and oxytetracycline in dogs. Antimicrob Agents Chemother 1975;8:713-20.

97. Petersen CS, Jørgensen B, Petersen NS. Treatment of early infectious syphilis in Denmark-a retrospective serological study. Dan Med Bull 1984;31:70-2. 